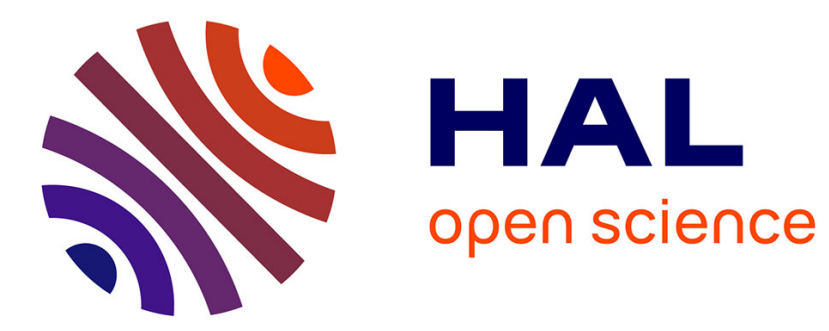

\title{
Deriving Information from Sensor Data
}

Marco Lewandowski, Klaus-Dieter Thoben

\section{To cite this version:}

Marco Lewandowski, Klaus-Dieter Thoben. Deriving Information from Sensor Data. 14th IFIP International Conference on Product Lifecycle Management (PLM), Jul 2017, Seville, Spain. pp.623-631, 10.1007/978-3-319-72905-3_55. hal-01764160

\section{HAL Id: hal-01764160 \\ https://hal.inria.fr/hal-01764160}

Submitted on 11 Apr 2018

HAL is a multi-disciplinary open access archive for the deposit and dissemination of scientific research documents, whether they are published or not. The documents may come from teaching and research institutions in France or abroad, or from public or private research centers.
L'archive ouverte pluridisciplinaire $\mathbf{H A L}$, est destinée au dépôt et à la diffusion de documents scientifiques de niveau recherche, publiés ou non, émanant des établissements d'enseignement et de recherche français ou étrangers, des laboratoires publics ou privés. 


\title{
Deriving Information from Sensor Data
}

\section{A general approach for the introduction of IoT technologies for field data analysis in complex technical systems}

\author{
Marco Lewandowski ${ }^{1 *}$ and Klaus-Dieter Thoben ${ }^{2}$ \\ ${ }^{1}$ BIBA - Bremer Institut für Produktion und Logistik GmbH, University of Bremen, Bremen, \\ Germany, lew@biba.uni-bremen.de \\ ${ }^{2}$ Institute for Integrated Product Development, University of Bremen, Bremen, Germany, \\ tho@biba.uni-bremen.de
}

\begin{abstract}
Not least because of the triumph of different IoT technologies, the uptake of sensor data during the use phase of complex technical systems has become mandatory. These data, especially in combination with additional field data, promise to improve the technical management of systems. Various concepts have also been developed to determine the usefulness of returning the data to product development. Regardless of whether the use of the field data analysis is carried out within the utilisation phase or over phase boundaries, it is also a great challenge to process the data in such a way that information and action-oriented knowledge are generated. The consolidation of results from different analyses to uniform priorities of systems and system components is crucial for the management of systems, for example with regard to decision support. Therefore, an approach is presented and discussed in order to support the systematic combination of methods for sensor field data evaluation. This includes both a general approach model and a corresponding system architecture both on a methodology level. This approach is illustrated by an example and leads to the conclusion that multiple analyses of sensor series using different methods together lead to more reliable information on system components. With regard to the summary of the contribution, the approach shows great potential for the faster introduction of field data analyses in companies, but further developments are required for the selection of the individual methods as well as for the data compaction itself.
\end{abstract}

Keywords IoT, Sensor data, Field data, Data analytics, Design methodology 


\section{Introduction}

So-called field data arises along the complete lifecycle of products essentially in the usage phase [1]. Besides traditional data sources that take into account maintenance reports, complaints, warranty cases, field service reports, etc. automatic data acquisition units by means of Internet of Things technology open up a huge potential for the target-oriented analysis of field data [2]. The amount of raw data that can be processed in order to gain action-oriented information for all kinds of business-related decisions is growing according to the growth of embedded IoT technology in products [3].

The challenge in dealing with field data consists in the systematic and efficient acquisition and then in the return of the field data for use in the first phases of the product lifecycle for instance when considering the development of a next product generation or the creation of product-related services [4]. Under the terms Big Data, Data Analytics, Predictive Analytics and similar ones, research and industry try to investigate in IT-based solutions encompassing advanced mathematical concepts to find "truths" that lay somewhere in the massive datasets of companies [5].

It is widely spread that algorithms for that purpose are more or less of general type, i.e. not dedicated to a particular problem or application domain. Actually, most of the recent developments in this field arise from the artificial intelligence domain, thus applying neural networks and deep learning to field data analysis [6]. While these approaches facilitate very powerful analytics tools, the generalissimo might be problematic from case to case as technical knowledge is required to understand and model cause-effect-relations within the analytical calculations. Otherwise, there is a not slight chance of detecting obvious correlations.

This leads to the requirement of defining approaches and concepts that explicitly take into account the "analytics engineering process" that will be performed as a creative process involving engineers, data scientists and IT specialists. In general no scientific work has been found on this issue, however, embedding data analytics as part of an operational management process is of great concern in enterprises.

In the remaining paper, we will sketch a possible approach on a methodology level which aims at the effective introduction of supporting technologies like Internet of Things (IoT), Big Data acquisition by means of Field Data acquisition and predictive analytics by means of modern algorithms from the field of artificial intelligence and deep learning. This concept takes into account the usage of data and the derived information for efficient operation and maintenance of complex technical systems as well as the backflow of information to research and design processes thus exploiting the complete lifecycle of individual products (at present excluding disposal, reuse or recycling at the end of life for the further discussion in this paper). Followed by a so-called experiment we will outline the effect of technology usage in order to derive information from data by an example. Finally, results and possible following research issues are given. 


\section{General Concept}

The introduction of technical support systems to implement condition-based operation and maintenance concepts, as well as the return of field data, technically requires an implementation project based on a methodological and applicationspecific system-analytical approach. This initially supports the development and integration of technical systems, such as Internet-of-Things technologies and socalled condition monitoring technologies. The collection of technical data on complex systems leads to the overall operational use of the system during the operating and maintenance phase and to optimise new product generations from the derived information [7].

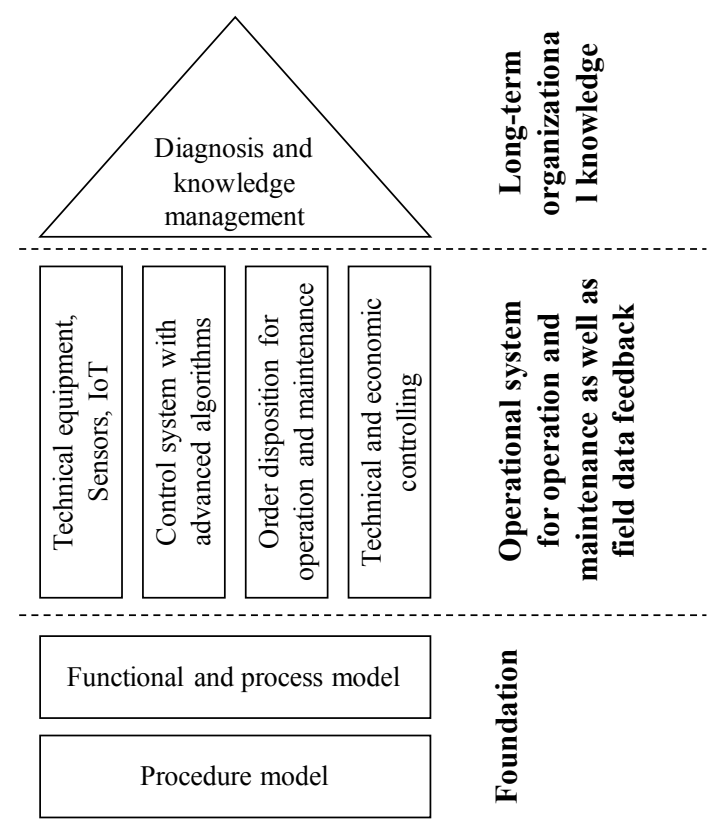

Fig. 2. Overarching model for the introduction of technical system to support operation and maintenance as well as field data feedback

As an overarching model for solving these challenges, different aspects must be taken into account in project development. Fig. 1 illustrates the systematics of the model. The basis is a modified approach model, which supports the project engineer during strategy adaptation, including the necessary technical structures. As part of the basic analysis phase, a functional and procedural model of the technical system under consideration is crucial in order to develop appropriate solutions from the outset.

On the further level is the actual detection system for the condition of the complex technical systems, which in the broader sense solves the essential challenges 
with regard to the data collection and evaluation and thus supports the operational tasks and measures within the framework of field data processing. It is subdivided into other self-contained but linked aspects (shown as vertical columns in Fig. 1):

First of all, this is the technical equipment of the technical system to be monitored, for example with sensors and IoT devices. In addition, the enrichment of information and knowledge should be designed as a rule-based framework in terms of decision-making encompassing domain-specific algorithms. With respect to the overall condition assessment of the entire complex technical system, the ambivalent outcome of different assessment algorithms should be brought together into a single indicator. The result, which describes, for instance, the perspective necessity of maintenance measures (i.e. inspection, maintenance and repair), are then to be used in the planning and control level, and are therefore decisive for the order disposition as an essential aspect of the planning and control. The final pillar, however, also includes the technical and economic controlling of the plants and the processes, the possibilities of which are to be brought more strongly into the focus due to the expected improved data situation in condition monitoring. This is used to address the return of field data as a further target.

With the transition from the operational area into the tactical and strategic planning horizon, a long-term organizational knowledge based on information from the field data is to be developed and to be used both during operation and maintenance as well as in the early stages of life of new product generations (in Fig. 1, this aspect is the overarching roof of the integration model). Overall, a particular focus is therefore on the integration of the different information and knowledge sources, both from the technical sensor and IoT systems as well as from the employee environment.

\section{Experiment}

Based on a case study carried out within the project "ISETEC II - Instandhaltung" supported by the Federal Ministry of Economics and Energy in Germany, the concept of the overarching model according to Fig. 1 has been exemplarily tested. The presented model is intended to explain how the engineering process can be carried out in order to achieve a useful condition monitoring application of a technically complex system. During the case study, a prototypical equipment of a special vehicle with condition monitoring systems was used. These were integrated into an information system for the operational control room and the maintenance management. The continuous documentation of the data also focussed on the systematic improvement of the technically complex system.

The special vehicle was a so-called straddle carrier, which is used in the port area to process standard ISO containers after discharge from the ship on the terminal ground or to place them on other traffic carriers. The following fig. 2 shows the schematic structure of a straddle carrier. 


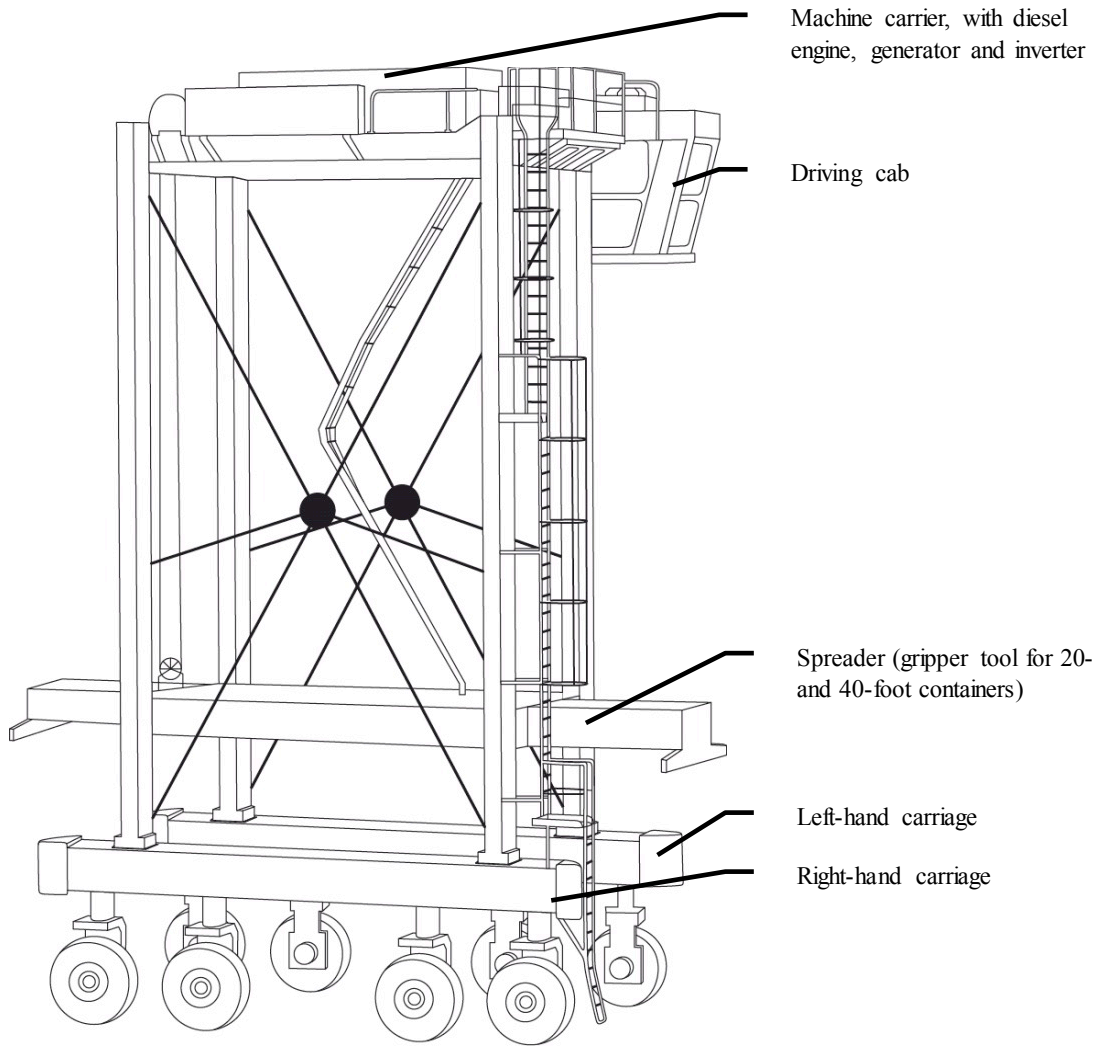

Fig. 2. Schematic design of a straddle carrier

The overriding task is to integrate a condition monitoring system based on sensors to be installed, which in conjunction with further field data from the utilisation phase provides a digital image of the system that is as continuous as possible. In the following, we briefly describe the application of the previously described model to the presented case. The focus lies on the explanation of possible contents in each element, providing an overarching description of the engineering tasks.

\section{Procedure Model}

Based on the proposed engineering model, the first step is the coordination of a specific procedure model. In the experimental application, the system is already existent in its main features and is also in use. Field data in the form of reports are available and acquired with the help of mobile technology. In order to assist the 
operation and maintenance phase as well as for the rebuild of the product life cycles in a digital record, it is intended to apply further sensor systems and condition monitoring technologies on the straddle carrier.

The procedure model accordingly has to take into account this aspect and could form a linear process consisting of the phases drafting of the supplement technology, development of the technology, integration into the decision support, commissioning and operation. The following Fig. 3 illustrates an appropriate procedure for the described case and gives some keywords about typical tasks in each phase of a project.

\begin{tabular}{|c|c|c|c|c|}
\hline Drafting & Development & Integration & Comissioning & Operation \\
\hline $\begin{array}{l}\text { Reverse engineering } \\
\text { Hierarchical } \\
\text { Analysis } \\
\text { Functional analysis }\end{array}$ & $\begin{array}{l}\text { Sensors } \\
\text { Condition } \\
\text { Monitoring } \\
\text { Integration on the } \\
\text { straddle carrier itself }\end{array}$ & $\begin{array}{l}\text { Algorithmic } \\
\text { processing } \\
\text { Further field data } \\
\text { IT-integration } \\
\text { Decision support }\end{array}$ & $\begin{array}{l}\text { Trials / testing } \\
\text { Learning (of } \\
\text { algorithms) } \\
\text { Planning of triggers } \\
\text { for actions / events }\end{array}$ & $\begin{array}{l}\text { Controlling } \\
\text { Improvement }\end{array}$ \\
\hline
\end{tabular}

Fig. 3. Specific procedure model based on the straddle carrier

\section{Functional and process model}

Both in the case of the development of completely new products as well as in the case of supplement equipping as described here, the functional model should be clear to identify the opportunities of field data analytics.

The first step in the introduction of IT-based technologies in the field thus comprises a detailed recording and analysis of the current state. It is fundamentally different in the available data sources whether the actual state is based on existing technical systems or whether the system is under consideration (still in the design and construction phase). With respect to the least mentioned, data from the real operation cannot yet be accessed. The functional and procedural model for the ascertainment of the actual as-is-state comprises five sub-areas:

A. The hierarchical structure of the system;

B. The functional structure of the system;

C. Key figures and characteristic values for the collection and documentation of the technical reliability based on the system structure;

D. The assessment of the technical reliability of individual system components;

E. The analysis and classification of additional existing maintenance-relevant data. 
For each of the subareas, methods can support the process; the following fig. 4 just gives an excerpt of a modelling technique for the functional structure of the straddle carrier.

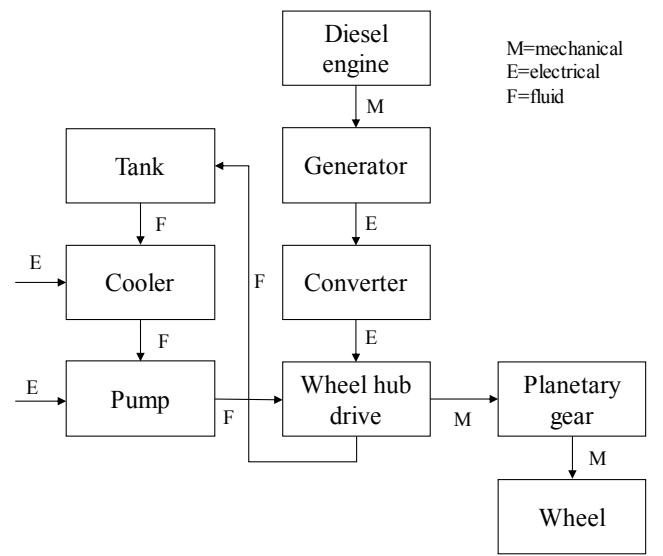

Fig. 4. Excerpt of a modelling technique for the functional structure of the straddle carrier

\section{Technical equipment, sensors, IoT}

The acquired knowledge about the actual state of a technical system as well as the planning of a target process for future handling of field data leads to the further steps of the integration project. Above all, the tools necessary for the determination of the condition as well as, subsequently, the methods required for the evaluation of data must be designed and dimensioned. This task is followed by a threestep process by first examining the appropriateness of a technology for the automated recovery of the condition. Based on this, the selection of a specific technique or a tool for determining the state is made by means of relevant technical parameters or other field data sources. Sometimes a combination of techniques and data sources is required. Finally, methods should be defined with which the measured data can be transferred into information about the state of the technical object under consideration.

\section{Control system with advanced algorithms}

The definition of the technical systems for recording physical parameters, which are intended to provide information on the state of a technical system, is followed by the requirement of a diagnostic system for detecting technical malfunctions. 
The integration of additional field data sources must be taken into account. If this system is initially considered superior, it consists of the following three modules:

A. Input the data from different sources and from the techniques of the recovery of the state,

B. Processing the input data with regard to abnormalities using the appropriate methods and methods

C. Derivation of a decision template as the output of the system.

While a) and b) have been dealt with in the previous sections, the concrete rule system has to be specified below. The known methods for compaction of raw data, for example from time series to corresponding information, are manifold and differ in terms of their output expenditure. Typical output forms of the methods are a) time series with a trend extrapolation, b) classification or categorization, c) statistical distributions or representations (e.g., histogram, Weibull distribution, etc.), d) key figure (e.g., MTBF, MTTR, etc.), etc.

In addition, the outputs or results of the different methods can also serve as input to a further method, which leads to cascaded calculations. From an application-oriented viewpoint, the exact configuration of accounting runs is to be provided in the course of the selection of the appropriate methods. Corresponding to this task, therefore, respective instances are to be generated and defined which, correspondingly parameterized, analyse one or more input data series. The combination of several simple procedures, as well as the use of more complex calculation algorithms in a single system, is made possible. As a prerequisite, a collection of methods is required, as well as a platform for their use and configuration with regard to the available data. Figure 5 below illustrates the basic process.

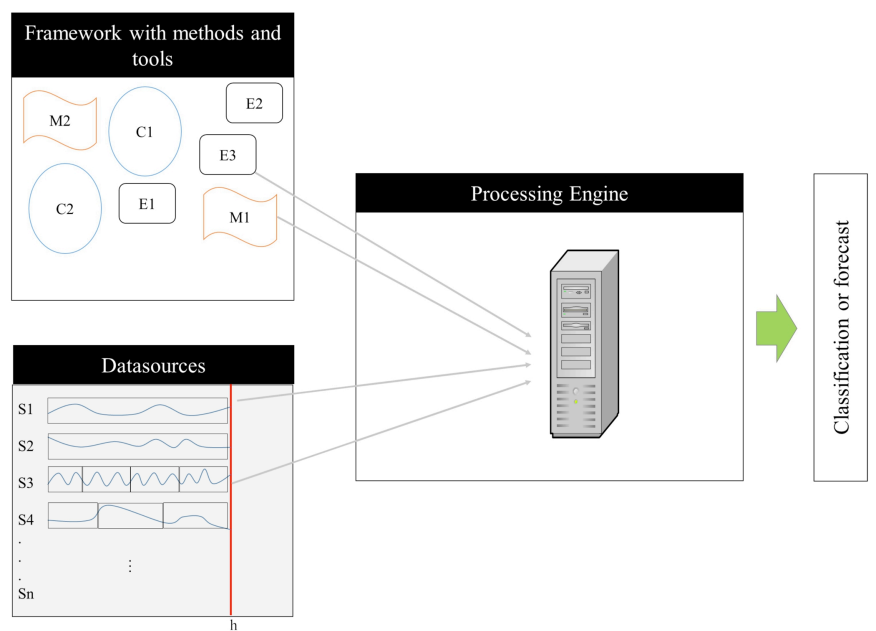

Fig. 5. Universal architecture for field data acquisition and analysis from sensors 


\section{Order disposition for operation and maintenance}

The processual and system-wide interconnection of the findings from the individual field data analysis increases the potential of the project. The objectives can be quite different.

In this context, it must be taken into account, in particular, that a direct information advance for the operation management and the maintenance management is created within the life phase. The focus here is primarily on people. It can also be checked whether evaluations can be directly linked from machine to machine.

\section{Technical and economic controlling}

The relatively long operating phase within the life cycle allows the continuous acquisition of data, which should be stored and archived for various purposes. This includes the documentation of performed activities for billing purposes and the fulfilment of regulated requirements, as well as the collection of data, information and knowledge about the technical system, in order to be able to plan and control operational optimisation projects based on a well-founded information basis. The goal here is the archiving of often implicitly existing knowledge from the company in an explicit database, in order to be able to access this knowledge more easily in the future as well as to prevent the danger of the loss of knowledge, for example by employee fluctuation.

\section{Diagnosis and knowledge management}

In the short and medium-term oriented controlling of maintenance measures the improvement of the processes and technical systems will follow themselves by the data-oriented consideration of the maintenance. This can be done, among other things, by incorporating maintenance data into the entire lifecycle view of technical systems. Life cycle management is to be understood as a holistic approach in which operational and operational optimisation efforts embrace the entire lifecycle of a product. The concept of closed-loop lifecycle management is understood as the concept of closed information circuits [8].

In addition to the use of data within the phase of operation and maintenance, the provision of information about the phase borders is also a means of establishing long-term organisational knowledge. 


\section{Summary and outlook}

This contribution made clear that the continuous use of field data, including the use of corresponding technical condition monitoring systems, requires a customised individual approach, which has been developed and proposed at this point in a generalized methodological form and detailed using a case. This allows interdisciplinary aspects of a project to be individually taken into account so that this paper provides a basic discussion about an acquisition, prioritisation and evaluation method for components of complex technical systems.

Furthermore, there is a concept for an information system which supports the transfer of the planning phase into the actual operating phase. With particular attention to different data sources, their evaluation and presentation, all the technologically relevant challenges of an integrated information system for field data have been taken up and designed in detail. Proposals for methodology have been developed and are only given as an example in this paper.

Clearly, above all, the basic necessity of a procedural model has been discussed. The further development of the framework with concrete methods and tools is to be continually developed further by means of further case studies.

\section{References}

1. David M, Rowe F (2016) What does PLMS (product lifecycle management systems) manage: Data or documents? Complementarity and contingency for SMEs. Computers in Industry 75: $140-150$

2. Främling K, Holmström J, Loukkola $\mathbf{J}$ et al. (2013) Sustainable PLM through Intelligent Products. Engineering Applications of Artificial Intelligence 26(2): 789-799

3. Zhang Y, Ren S, Liu Y et al. (2017) A big data analytics architecture for cleaner manufacturing and maintenance processes of complex products. Journal of Cleaner Production 142: 626-641

4. Sakao T, Lindahl M (eds) (2009) Introduction to Product/Service-System Design. SpringerVerlag London, London

5. Zhong RY, Newman ST, Huang GQ et al. (2016) Big Data for supply chain management in the service and manufacturing sectors: Challenges, opportunities, and future perspectives. Computers \& Industrial Engineering 101: 572-591

6. Wuest T, Weimer D, Irgens $C$ et al. (2016) Machine learning in manufacturing: Advantages, challenges, and applications. Production \& Manufacturing Research 4(1): 23-45

7. Lützenberger J, Klein P, Hribernik K et al. (2016) Improving Product-Service Systems by Exploiting Information From The Usage Phase. A Case Study. Procedia CIRP 47: 376-381

8. Kiritsis D (2011) Closed-loop PLM for intelligent products in the era of the internet of things. Computer-Aided Design 43(5): 479-501 